\title{
IdeAs
}

Idées d'Amériques

$8 \mid 2016$

Ressources minières dans les Amériques: Mutations d'un continent

\section{Autour de l'exposition du Grand Palais « Mexique 1900-1950. Diego Rivera, Frida Kahlo, José Clemente Orozco et les avant-gardes "}

\section{Paul-Henri Giraud}

\section{(2) OpenEdition}

\section{Journals}

Édition électronique

URL : https://journals.openedition.org/ideas/1726

DOI : 10.4000/ideas. 1726

ISSN : 1950-5701

Éditeur

Institut des Amériques

Référence électronique

Paul-Henri Giraud, « Autour de l'exposition du Grand Palais « Mexique 1900-1950. Diego Rivera, Frida Kahlo, José Clemente Orozco et les avant-gardes » », IdeAs [En ligne], 8 | 2016, mis en ligne le 20 décembre 2016, consulté le 18 octobre 2022. URL : http://journals.openedition.org/ideas/1726 ; DOI https://doi.org/10.4000/ideas.1726

Ce document a été généré automatiquement le 18 octobre 2022

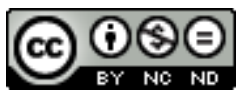

Creative Commons - Attribution - Pas d'Utilisation Commerciale - Pas de Modification 4.0 International - CC BY-NC-ND 4.0

https://creativecommons.org/licenses/by-nc-nd/4.0/ 


\title{
Autour de l'exposition du Grand Palais « Mexique 1900-1950. Diego Rivera, Frida Kahlo, José Clemente Orozco et les avant-gardes »
}

\author{
Paul-Henri Giraud
}

1 «L'année du Mexique en France » programmée en 2011 aurait dû marquer l'excellence des relations bilatérales entre les deux pays. Une liste imposante de manifestations culturelles était organisée, mais tout fut annulé au dernier moment en raison d'un différend diplomatique. L'affaire Florence Cassez, du nom de la jeune Française alors incarcérée à Mexico, avait définitivement brouillé les Présidents Nicolas Sarkozy et Felipe Calderón. En 2014, le voyage officiel de François Hollande au Mexique scella la réconciliation entre les deux pays ; il fut suivi, en 2015, de la visite d'Enrique Peña Nieto en France et de son invitation d'honneur au défilé du 14 juillet.

2 C'est donc en 2016 seulement qu'une grande exposition d'art mexicain a pu être montée au Grand Palais, temple incontesté des expositions internationales parisiennes. Le site officiel du musée la désigne comme « la plus grande manifestation consacrée à l'art mexicain depuis $1953 »^{1}$, ce qui est vrai, en tout cas, pour les expositions françaises. Il est en revanche assez inexact d'affirmer que «le parcours dresse un constat de la bouillonnante créativité artistique du pays tout au long du $\mathrm{XX}^{\mathrm{e}}$ siècle » (ibid.) : l'exposition commence par quelques œuvres du XIXe siècle et, conformément à son titre, ne s'aventure guère au-delà de 1950 . Elle présente donc une période très proche de celle montrée au Musée d'art moderne de Lille Métropole, Villeneuve d'Ascq, en 2004 (Mexique-Europe. Allers-Retours. 1910-1960) et met en valeur, dans son sous-titre, le même couple mythique qui a récemment eu les honneurs du Musée de l'Orangerie (Frida Kahlo, Diego Rivera. L'art en fusion, 2013-2014). Voilà, à n'en pas douter, un ticket gagnant. Pour découvrir en France les générations artistiques suivantes, il faudra attendre d'autres expositions. 
3 Celle du Grand Palais a néanmoins le mérite de montrer pour la première fois au grand public français un certain nombre d'artistes méconnus en Europe, comme s'en félicite Serge Fauchereau dans l'interview qui ouvre ce dossier. Adriana Ortega Orozco rappelle que cette exposition s'inscrit dans une forte tradition de la diplomatie mexicaine, pratiquée dès les années 1920 grâce à l'invention d'un nationalisme culturel vigoureux, et consolidée dans les années 1940-1950 avec l'«institutionnalisation» de la Révolution. Que cette politique ait puissamment servi la promotion et l'autopromotion d'un artiste aussi «fabuleux » que Diego Rivera, c'est ce que montre l'essai d'Ana Cecilia Hornedo Marín.

4 La réalisation en 2016 de cette exposition offre l'avantage inopiné de coïncider avec celle actuellement présentée à l'Orangerie sous le titre La peinture américaine des années 1930. "The Age of Anxiety". Impossible d'imaginer deux affiches plus différentes. D'un côté, une belle indienne aux courbes plantureuses se prélasse au bord d'une rivière éden indigène : les bons sauvages à peine métissés du Río Juchitán, dessinés à grands traits et coloriés avec un bonheur évident par Diego Rivera en 1953-1955. De l'autre, le grave double portrait à l'exactitude flamande, entre humour et anxiété, d'American Gothic (1930), par Grant Wood : le paradis perdu des fermiers de l'Iowa n'était pas drôle tous les jours... Le va-et-vient entre ces deux expositions que tout oppose - en apparence - n'est pas le moindre plaisir de cette saison parisienne.

\section{NOTES}

1. http://www.grandpalais.fr/fr/evenement/mexique-1900-1950, site consulté le 10.12.16.

\section{AUTEUR}

\section{PAUL-HENRI GIRAUD}

Professeur en études hispaniques contemporaines à l'Université de Lille Sciences humaines et sociales, il est directeur adjoint du Centre d'études en civilisations, langues et littératures étrangères (CECILLE) et Secrétaire général de l'Institut des Amériques. Il a publié Octavio Paz : Vers la transparence (2002, édition en espagnol revue et augmentée 2014) et Manuel Álvarez Bravo : L'Impalpable et l'imaginaire (2012). Il a récemment participé à l'édition de 1910: México entre dos épocas (2014); Le travail du visible: Claude Esteban et les arts plastiques (2014); Fotografía, cultura y sociedad en América latina. Nuevas perspectivas, numéro 219 de L'Ordinaire des Amériques (http:// orda.revues.org), décembre 2015. paul-henri.giraud@univ-lille3.fr 